\title{
Morphology and growth rate of calcium carbonate crystals in a gas-liquid-solid reactive crystallizer
}

\author{
Pao-Chi Chen, ${ }^{*}{ }^{\dagger}$ Clifford Y. Tai ${ }^{\ddagger}$ and K. C. Lee ${ }^{\ddagger}$ \\ * Department of Chemical Engineering, Lunghwa Junior College of Technology and \\ Commerce, Kuei-Shan, Tao-Yuan, No 300 Sec 1, Wan Sou Road. Tao-Yuan, Taiwan; \\ 'Department of Chemical Engineering, National Taiwan University, Taipei. Taiwan
}

(Accepted 1 July 1997)

\begin{abstract}
The polymorphism of calcium carbonate crystal was studied by introducing $\mathrm{CO}_{2}$ gas through a gas sparger or a double-tube gas injection nozzle into a $\mathrm{pH}$-stat crystallizer containing calcium chloride solution. Several operating variables were investigated and the $\mathrm{pH}$ of solution and calcium ion concentration were the important factors that affect the formation of polymorphs of calcium carbonate. At ambient temperature either calcite or vaterite was the major product, depending on the $\mathrm{pH}$ and calcium ion concentration. Then the same crystallization system was employed to study the growth kinetics of calcite crystals, using a double-tube gas injection nozzle instead of a gas sparger, which cannot be used to suppress nucleation, to introduce the $\mathrm{CO}_{2}$ gas into the crystallizer. The growth rates of calcite seeds increased with increasing supersaturation and crystal size. As a conclusion. the polymorphs and growth rate of calcium carbonate are controllable in a gas-liquid-solid reactive crystallizer. using a $\mathrm{pH}$-stat operation mode. (\$) 1997 Elsevier Science Ltd
\end{abstract}

Keywords: Polymorphism: calcium carbonate; crystal growth; gas-liquid -solid system; twostep growth model; induction period.

\section{INTRODUCTION}

Calcium carbonate is a widely used chemical in various industries and an abundant compound found in the nature. The crystallization phenomena of this sparingly soluble salt are very complicated because it precipitates in three crystalline forms, including calcite, aragonite, and vaterite, and the operating variables, such as the $\mathrm{pH}$ of solution. solution composition, temperature, and ionic strength, are interrelated and interact on each other in a crystallization process.

The liquid liquid-solid reactive processes are often adopted in a laboratory study because of its simplicity in the operation or its easiness in the control of process variables. For example, Wray and Daniels (1957) investigated the polymorphs of calcium carbonate precipitates by mixing soluble carbonate solutions with solutions of calcium ions under conditions of controlled temperature, concentration, and aging; Sohnel and Mullin (1982) determined the growth rate of crystals by a desupersaturation method

\footnotetext{
'Corresponding author. Tel.: 0088629023211 ; fax: 00886 29044650 .
}

and explored the effects of impurities on crystal morphology; Hostomsky and Jones (1991) found that the crystal form was dependent on the residence time, $\mathrm{pH}$, and the concentration of reagents in an MSMPR crystallizer; Tai et al. (1993) and Koutsoukos (1993) studied the growth kinetics and morphology using a pH-stat method; Tai et al. (1995) and Wojcik and Jones (1997) investigated the dynamic and kinetic behaviors in the agglomeration process of $\mathrm{CaCO}_{3}$ precipitates: and Isopescu et al. (1996) analyzed the crystallization data based on the size-dependent growth model. However, the precipitated calcium carbonate are produced commercially by passing carbon dioxide through a milk of lime, i.e. by a gas-liquid solid reacting method. Studies on gas liquid "solid systems are rare because the process variables are interrelated and are difficult to control as compared with the liquid-liquid--solid systems. The report by Yagi e' al. (1984) was perhaps the first one to systematically study the three-phase system. However. the crystallizer used was a stirred vessel with a flat gas -liquid interface, which has no practical use. Besides, there was no control of the $\mathrm{pH}$ of solution during the course of precipitation. Jones and his coworkers (Wachi and Jones, 1991; Jones et al., 1992) continued to perform similar experiments and 
modeled the crystal size distribution of $\mathrm{CaCO}_{3}$ precipitates with some degree of success. Kojima et al. (1992) studied the crystal morphology of calcium carbonate which was precipitated by outgassing dissolved $\mathrm{CO}_{2}$ in calcium hydrogencarbonate solution. Although the $\mathrm{pH}$ of solution was not controlled during the precipitation process, they were able to produce rhombohedral-like calcite, prismoidal-like aragonite, and hexagonal plate-like vaterite with the initial $\mathrm{pH}$ of solution varying between 6.2 and 8.0 and the temperature between 20 and $100 \mathrm{C}$.

In our laboratory a gas-liquid-solid reactive crystallizer was employed to study the polymorphs of calcium carbonate and the growth rate of calcite crystal, which is the thermodynamically stable form of calcium carbonate at atmospheric pressure and ambient temperature. The $\mathrm{CO}_{2}$ gas was introduced into the crystallizer, in which the concentration of hydrogen ion was maintained at a constant level by using a $\mathrm{pH}$ stat apparatus, through a double-tube injection nozzle or a gas sparger. Several process variables, including the $\mathrm{pH}$ of solution, concentration of calcium ion, concentration ratio of $\left[\mathrm{HCO}_{3}\right] /\left[\mathrm{CO}_{3}^{-2}\right]$, and gas liquid mixing mode were investigated. The results on the polymorphs of calcium carbonate and the crystal growth kinetics of calcite were compared with those obtained from the liquid-liquid-solid systems.

\section{EXPERIMENTAL}

A schematic diagram of the semibatch crystallization apparatus is shown in Fig. 1. It consists of a pHstat autotitrator (Kyoto Electronic AT 200), an ion meter (Orion EA 920), a 1.51 acrylic crystallizer, a constant-temperature water batch, and a double-tube gas injection nozzle or a gas sparger. The diameter and height of the crystallizer, fitted with four baffies at $90^{\circ}$ spacing, are 120 and $140 \mathrm{~mm}$, respectively. The construction of the double-tube gas injection nozzle followed the design of Kubota et al. (1990) as shown in Fig. 2. The advantage of this design is to avoid nucleation in the outer tube, where $\mathrm{CO}_{2}$ gas contacts with solution bearing a low $\mathrm{pH}$. The $\mathrm{pH}$ of solution was measured by means of a pair of glass (Kyoto Electronic $\mathrm{H}-112$ ) and reference (Kyoto Electronic R-116) electrodes, standardized before each experiment with standard buffers of $\mathrm{pH} 6.86$ and 9.18. The $\mathrm{CO}_{2}$ gas dissolved in solution as carbonates was measured by a $\mathrm{CO}_{2}$-electrode (Orion Research), which was calibrated with a standard solution of sodium carbonate. All the experiments were conducted at $30^{\circ} \mathrm{C}$.

The experiments were first performed for the study of crystal morphology. A solution of desired concentration was prepared using the calcium chloride crystals as received (Merck, EP Grade) and deionized water. After being filtered, $1 \mathrm{l}$ of solution was transferred to the crystallizer with the impeller running at $600 \mathrm{rpm}$, which is high enough to suspend $\mathrm{CaCO}_{3}$ crystals in all experiments conducted in this study. Then the $\mathrm{pH}$ of solution was adjusted to a desired value by adding drops of $0.1 \mathrm{M} \mathrm{KOH}$ solution. After the $\mathrm{pH}$ became steady. we opened the regulator of $\mathrm{CO}_{2}$ gas cylinder and let the $\mathrm{CO}_{2}$ gas flow through the injection nozzle to contact with the solution. The $\mathrm{pH}$ of solution was maintained at a constant level during the operation by constantly adding $\mathrm{KOH}$ solution, which was controlled by the autotitrator. The concentration of solution was kept in the labile region, where the supersaturation is so high that the primary nucleation would occur to produce nuclei, of a precipitation diagram which was plotted previously (Chen, 1995) and was shown in Fig. 3. The calcium carbonate was precipitated after an induction period. and the operating time varied from 30 to $100 \mathrm{~min}$, depending on the production rate of precipitates. In the course of reactive precipitation. a solution of $2.5 \mathrm{ml}$ was withdrawn from the crystallizer every $3 \mathrm{~min}$ and was filtered with a $0.22 \mu \mathrm{m}$ membrane to remove solid particles for subsequent analysis of $\mathrm{Ca}^{2+}$ concentration using the atomic absorption method. Finally, after the precipitated particles were filtered and dried, the morphology of precipitates was examined by a scanning electron microscope and the fraction of polymorphs was determined by a X-ray powder diffractometer.

The experimental procedures in the crystal growth study were somewhat different from that of morphology study. A certain amount of calcite seeds were added to the crystallizer after the $\mathrm{pH}$ of solution became steady. Besides, the flow of $\mathrm{CO}_{2}$ gas was

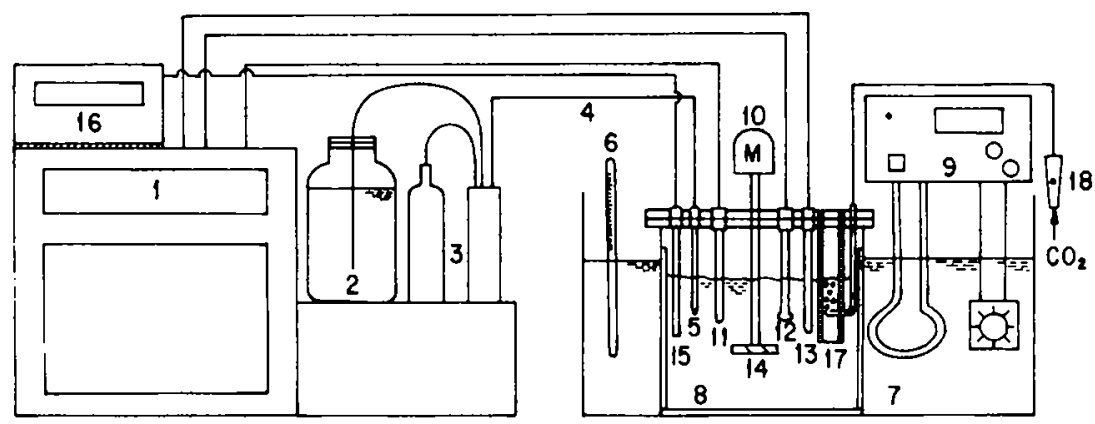

Fig. 1. Schematic diagram of $\mathrm{pH}$-stat crystallization system. 


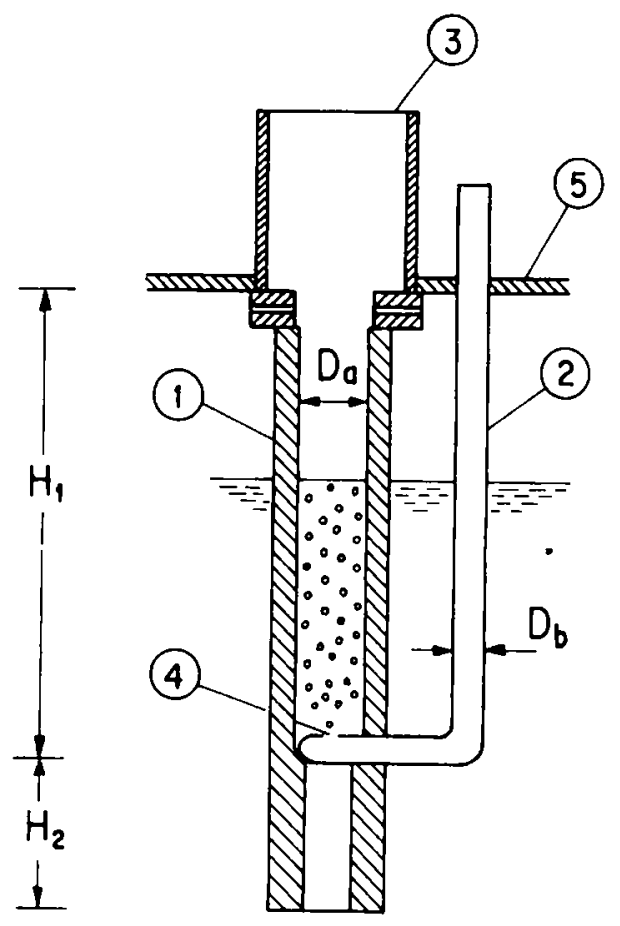

Fig. 2. Detailed structure of double-tube gas injection nozzle. (1) outer tube, (2) gas inlet tubc. (3) upper opening, (4) orifice. (5) lid. $D_{a}=11 \mathrm{~mm}, D_{b}=3 \mathrm{~mm} . H_{1}=100 \mathrm{~mm}$, $H_{2}=18 \mathrm{~mm}$.

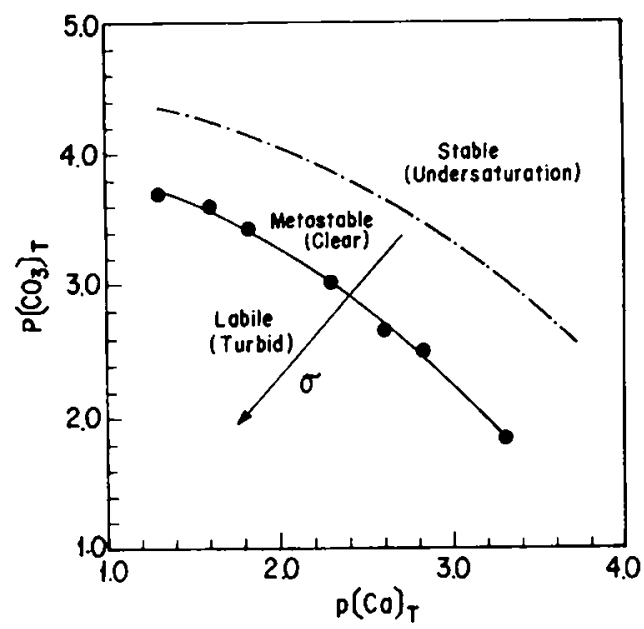

Fig. 3. Precipitation diagram of calcium carbonate.

adjusted to a slower rate so that the concentration of solution fell in the metastable region of Fig. 3, in which the seed crystals grew without nucleation. Four sizes of seeds, i.e. $68,163,230$, and $328 \mu \mathrm{m}$, were prepared by the gel growth technique, which has been described elsewhere (Tai et al., 1993). The smallest seed crystals studied in this experiment were $20 \mu \mathrm{m}$ in size, which was obtained by screening the calcite as received from Nacalai Tseque Company. The morphology of all seed crystals is rhombohedron.

\section{DETERMINATION OF RELATIVE SUPERSATURATION} AND CRYSTAL GROWTH RATE

\subsection{Relative supersaturation}

The relative supersaturation, $\sigma$, used in this work was defined by Nielsen and Toft (1984):

$$
\sigma=\left(\Pi: K_{s p}\right)^{1.2}-1
$$

where $\Pi$ is the ionic product and $K_{s p}$ is the solubility product. When the $\mathrm{pH}$ of solution, total calcium ion concentration, total carbonate concentration, and activity coefficient equation were known, the concentrations of ionic species were calculated by the method of successive approximation for the ionic strength (Nancollas, 1966: Tai et al., 1993).

\subsection{Determination of crystal growth rate}

The mass growth rate per unit surface area of crystal can be expressed as follows:

$$
\frac{1}{A} \frac{\mathrm{d} m}{\mathrm{~d} t}=\frac{\rho_{\mathrm{s}}}{A} \frac{\mathrm{d} V_{\mathrm{s}}}{\mathrm{d} t}=\frac{3 \rho_{\mathrm{s}} / f_{\mathrm{r}}}{f_{\mathrm{s}}} \frac{\mathrm{d} L}{\mathrm{~d} t}
$$

where $A, V_{\mathrm{s}}$ and $\rho_{\mathrm{s}}$ are the surface area, volume, and density of seed crystals, respectively. The linear growth rate is related to the mass growth rate by the following equation.

$$
G=\frac{\mathrm{d} L}{\mathrm{~d} t}=\frac{f_{\mathrm{s}}}{3 f_{s} \rho_{s} A} \frac{\mathrm{d} m}{\mathrm{~d} t}
$$

where mass growth rate, $\mathrm{d} m / \mathrm{d} t$, can be estimated from the depletion of calcium ion.

$$
\frac{\mathrm{d} m}{\mathrm{~d} t}=M V\left(-\frac{\mathrm{d}\left[\mathrm{Ca}^{2+}\right]}{\mathrm{d} t}\right)
$$

where $M$ is the molecular weight of calcium carbonate, $V$ the volume of solution, and $\left[\mathrm{Ca}^{2+}\right]$ the molar concentration of calcium ion. Because the crystal form of calcite is rhombohedron, the value of $f_{s}: 3 f_{1}$. is close to 2. Substituting this value and eq. (4) into eq. (3), the linear growth rate becomes:

$$
G=\frac{\mathrm{d} L}{\mathrm{~d} t}=\frac{2 M V}{\rho_{\mathrm{s}} A}\left(-\frac{\mathrm{d}\left[\mathrm{Ca}^{2+}\right]}{\mathrm{d} t}\right) .
$$

Equation (5) describes the linear growth rate as a function of calcium ion concentration. Once the concentration profilc of calcium ion is available. the linear growth rate can be calculated at any instance of an experiment.

\subsection{Growth rate model}

Although the crystal growth rates may be influenced simultaneously by two or more mechanisms, the two-step model is commonly used to express a growth process as follows:

$$
\begin{gathered}
G=K_{d}\left(\sigma-\sigma_{i}\right)=K_{d 0} L^{a}\left(\sigma-\sigma_{i}\right) \text { (bulk diffusion) (6) } \\
-K_{r} \sigma_{i}^{r}=K_{r 0} L^{h} \sigma_{i}^{r} \quad \text { (surface integration). }
\end{gathered}
$$


Combining eqs (6) and (7) by eliminating $\sigma_{i}$, the resultant equation is

$$
\sigma=\frac{G}{K_{d 0} L^{a}}+\left(\frac{G}{K_{r 0} L^{b}}\right)^{1 \cdot r}
$$

Parameters $a, b, K_{d 0}$, and $K_{r 0}$ in eq. (8) can be evaluated by a nonlinear regression method for a given value of $r$, when the supersaturation and growth rate data are available.

\section{RESLLTS AND DISCUSSION}

\subsection{Supersaturation and induction period}

During the course of precipitation the supersaturation varied with time due to the accumulation or depletion of constituents. Figure 4 shows the change of relative supersaturation for various levels of $\mathrm{pH}$ under a constant flow rate of $\mathrm{CO}_{2}$ gas. All the curves in Fig. 4 exhibit a maximum, which approximately corresponds to the induction period because the decrease in supersaturation was caused by the commencement of nucleation. Therefore, the induction period of higher $\mathrm{pH}$ was shorter than that of lower pH. Besides, two different shapes of supersaturation curves are observed in Fig. 4; the changes in supersaturation for lower $\mathrm{pH}$ were moderate as compared with that of higher $\mathrm{pH}$. The possible reasons are given below. The absorption rate of $\mathrm{CO}_{2}$ was higher at higher $\mathrm{pH}$ (Sherwood et al., 1975; Butler, 1982) so that the supersaturation increased sharply for higher $\mathrm{pH}$, starting with approximately the same $\mathrm{Ca}^{2-}$ concentration for all levels of $\mathrm{pH}$. Then, high nucleation rate at high supersaturation gave a quick drop in supersaturation.

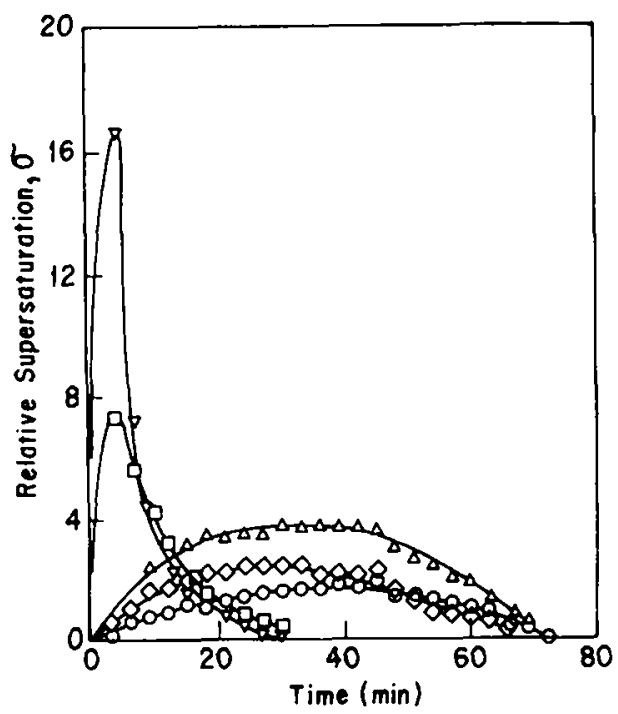

Fig. 4. Supersaturation profile of various levels of $\mathrm{pH}(\nabla)$ $\mathrm{pH}=9.0$. (只) $\mathrm{pH}=8.8,(\Delta) \mathrm{pH}=8.4,(\diamond) \mathrm{pH}=8.2$, (O) $\mathrm{pH}=8.0$

\subsection{Polymorphs of calcium carbonate}

Thirty-three runs of experiment were conducted in this work to study the polymorphs of calcium carbonate. The percentage of polymorphs produced and the operating conditions are listed in Table 1. The $\mathrm{pH}$ range investigated was between 7.8 and 9.4 . When the $\mathrm{pH}$ is lower than 7.8. the amount of precipitates produced was small. On the other hand, the control of the $\mathrm{pH}$ was difficult at higher $\mathrm{pH}$. The carbonate ion concentration and bicarbonate ion concentration were calculated at the highest relative supersaturation, $\sigma_{m}$. Then the ratio of bicarbonate ion concentration to carbonate ion concentration, $\mathrm{Cr}$. was plotted against calcium ion concentration for different values of $\mathrm{pH}$ as shown in Fig. 5. It is surprising to see that the $C r$ value decreases with increasing $\mathrm{Ca}^{2+}$ concentration at lower $\mathrm{pH}$ values. Under our operating conditions, the $\mathrm{pH}$ of solution is the most important factor that influences the formation of polymorphs of calcium carbonate. Nearly, pure products of vaterite were produced at $\mathrm{pH}$ below 8.0. The concentration of calcium ion seems to be a minor factor in the determination of vaterite. This result is contradictory to that reported by Yagi et al. (1984). They found that vaterites were produced at low $\mathrm{Ca}^{2}+$ concentration $(<0.4 \mathrm{mM})$. However, the $\mathrm{pH}$ of solution was not measured in their experiments. The maximum yield of calcites occurs somewhere around the $\mathrm{pH}$ of 8.6 for each series of experiment at a specified range of calcium ion concentration. This result is similar to that reported by Hostomsky and Jones (1991), who found that the maximum yield for calcite appeared at a $\mathrm{pH}$ of 8.5. The yield of calcite is also related to calcium ion concentration and gas dispersion method. The yield is highest for run 24. which has a high $\mathrm{Ca}^{2+}$ concentration $(15.9 \mathrm{mM})$. The results are consistent with that reported by Yagi et al. (1984) and Wachi and Jones (1991). When the $\mathrm{CO}_{2}$ gas was introduced into the crystallizer through a gas sparger in the experimental series I and II. the yield of calcite at a similar calcium ion concentration is higher than that of the experiments (series III and V) using the double-tube gas injection nozzle. As for aragonite. a small amount was produced at $30^{\circ} \mathrm{C}$ for high $\mathrm{pH}$ and calcium ion concentration irrespective of the gasdispersion method.

\subsection{Growth rate of calcite crystals}

In the growth rate study, the $\mathrm{CO}_{2}$ gas was introduced to the crystallizer through the double-tube injection nozzle. When a gas sparger was used, the suppress of nucleation in the crystallizer was not successful. Therefore, a comparison of growth-rate data between the two modes of gas dispersion is impossible. Growth rate of calcite crystals were estimated by eq. (5) using the slope of $\mathrm{Ca}^{2}$ concentration profile, which is shown in Fig. 6 for three typical runs. In principle, growth rate of any instance can be obtained from a $\left[\mathrm{Ca}^{2+}\right]-t$ curve. Actually, the growth rates were calculated at a time interval of 10 or $20 \mathrm{~min}$. depending on the steepness of $\left[\mathrm{Ca}^{2+}\right]-t$ curve. The 
Table 1. Crystal polymorphs of calcium carbonate at various operating conditions

\begin{tabular}{|c|c|c|c|c|c|c|c|c|c|}
\hline \multirow{2}{*}{$\begin{array}{l}\text { Series } \\
\text { no. }\end{array}$} & \multirow{2}{*}{$\begin{array}{l}\text { Run } \\
\text { no. }\end{array}$} & \multirow{2}{*}{$\begin{array}{c}{\left[\mathrm{Ca}^{-2}\right]_{i}} \\
(\mathrm{mM})\end{array}$} & \multirow[t]{2}{*}{$\mathrm{pH}$} & \multirow{2}{*}{$\begin{array}{c}{\left[\mathrm{HCO}_{3}^{-\cdots}\right]_{m}} \\
(\mathrm{mM})\end{array}$} & \multirow{2}{*}{$\begin{array}{c}{\left[\mathrm{CO}_{3}^{2}\right]_{m}} \\
(\mathrm{mM})\end{array}$} & \multirow[t]{2}{*}{$\sigma_{m}$} & \multicolumn{3}{|c|}{ Crystal polymorphs } \\
\hline & & & & & & & $V(\%)$ & $C(\%)$ & $A(\%)$ \\
\hline \multirow[t]{6}{*}{$\mathbf{I}$} & 1 & 8.44 & 7.80 & 42.86 & 0.23 & 7 & 100 & & -- \\
\hline & 2 & 8.64 & 8.00 & 63.84 & 0.56 & 9 & 86.5 & 13.4 & \\
\hline & 3 & 8.46 & 8.20 & 55.48 & 0.85 & 12 & 84.3 & 15.8 & \\
\hline & 4 & 8.43 & 8.40 & 28.61 & 0.58 & 11 & 86.2 & 13.7 & \\
\hline & 5 & 8.00 & 8.60 & 44.74 & 1.45 & 15 & 63.9 & 31.2 & 4.7 \\
\hline & 6 & 8.56 & 8.80 & 26.10 & 1.33 & 15 & 33.7 & 62.9 & 3.2 \\
\hline \multirow[t]{6}{*}{ II } & 7 & 4.44 & 7.80 & 50.79 & 0.27 & 3.5 & 100 & & .. \\
\hline & 8 & 3.61 & 8.00 & 24.54 & 0.19 & 4.5 & 90 & 9.0 & - \\
\hline & 9 & 3.61 & 8.20 & 26.47 & 0.35 & 7 & 80.2 & 19.7 & \\
\hline & 10 & 4.46 & 8.40 & 33.98 & 0.68 & 9 & 30.7 & 69.2 &.- \\
\hline & 11 & 4.44 & 8.60 & 19.16 & 0.49 & 10 & 89.8 & 10.1 & $\cdots$ \\
\hline & 12 & 4.44 & 8.80 & 15.30 & 0.69 & 10.5 & 74.4 & 8.0 & 17.6 \\
\hline \multirow[t]{7}{*}{ III } & 13 & 5.08 & 7.80 & 25.50 & 0.14 & 3.9 & 100 & -- & \\
\hline & 14 & 5.08 & 8.20 & 18.74 & 0.23 & 7 & 100 & . & - \\
\hline & 15 & 5.08 & 8.40 & 44.76 & 0.94 & 11 & 84.6 & 15.3 & - \\
\hline & 16 & 5.36 & 8.60 & 42.49 & 1.43 & 13 & 76.8 & 23.1 & \\
\hline & 17 & 5.30 & 8.80 & 30.19 & 1.49 & 15 & 77.1 & 22.8 & -.. \\
\hline & 18 & 5.34 & 9.00 & 12.32 & 0.87 & 14 & 68.9 & 8.0 & 23.1 \\
\hline & 19 & 5.44 & 9.20 & 7.24 & 0.79 & 12 & 77.6 & $\ldots$. & $22 . .3$ \\
\hline \multirow[t]{8}{*}{ IV } & 20) & 13.50 & 7.80 & 11.48 & 0.05 & 2.9 & 100 & $\ldots$ & \\
\hline & 21 & 14.00 & 8.00 & 12.22 & 0.14 & 6.5 & 100 & & \\
\hline & 22 & 15.30 & 8.20 & 20.20 & 0.41 & 9 & 77.8 & 22.1 &.- \\
\hline & 23 & 13.99 & 8.40 & 20.36 & 0.55 & 12 & 42.9 & 57.1 & \\
\hline & 24 & 15.90 & 8.60 & 18.80 & 0.66 & 17 & 22.1 & 77.8 & - \\
\hline & 25 & 20.00 & 9.00 & 6.25 & 0.42 & 15 & 71.8 & 28.1 & \\
\hline & 26 & 16.63 & 9.20 & 5.64 & 0.60 & 22 & 77.8 & .. & 22.3 \\
\hline & 27 & 16.69 & 9.40 & 9.18 & 1.27 & 22 & 73.8 & & 26.2 \\
\hline \multirow[t]{6}{*}{$\mathrm{v}$} & 28 & 3.03 & 8.00 & 23.46 & 0.18 & 2.1 & 95.0 & 5.0 & - \\
\hline & 29 & 3.09 & 8.20 & 13.99 & 0.16 & 2.5 & 85.6 & 14.3 & \\
\hline & 30 & 3.09 & 8.40 & 20.35 & 0.38 & 3.8 & 82.3 & 17.7 & \\
\hline & 31 & 3.18 & 8.60 & 11.42 & 0.32 & 4.3 & 74.0 & 26.0 & - \\
\hline & 32 & 2.96 & 8.80 & 6.32 & 0.26 & 7.3 & 81.9 & 18.1 & - \\
\hline & 33 & 2.90 & 9.00 & 8.66 & 0.60 & 10.6 & 81.9 & 18.1 & - \\
\hline
\end{tabular}

V: Vaterite; C: Calcite; A: Aragonite

crystal growth data of the seeds of various sizes were plotted against the relative supersaturation as shown in Fig. 7. The crystal growth rates increase with increasing supersaturation and crystal size. Using the two-step growth model, the parameters in eq. (8) were estimated by a nonlinear regression method for smaller crystal sizes, including 20,68 and $163 \mu \mathrm{m}$. The growth-rate data of larger sizes were excluded in the analysis because the increase in growth rate was not significant.

The regressed growth-rate equation is presented as follows.

$$
\begin{aligned}
G & =5.54 \times 10^{-9} L^{0.860}\left(\sigma-\sigma_{i}\right) \\
& =4.40 \times 10^{-11} L^{0.503} \sigma_{i}^{2.90}
\end{aligned}
$$

The mass-transfer and surface-integration rates are related to crystal size. This kinetic behaviors are com- monly observed in crystal growth processes (Tai et al.. 1993). The kinetic order of surface integration step is 2.9, which is higher than 2 found in a liquid-liquid reacting system (Tai et al., 1993) and is close to 3.0 reported by Qiu and Rasmuson (1990) for succinic acid.

Once the parameters in the growth-rate model are known, the controlling step of growth process can be judged by the effectiveness factor proposed by Garside (1971). The surface-integration effectiveness factor for an $r$ th-order process is

$$
\eta=(1-\eta D a)^{r}
$$

where

$$
D a=K_{r 0} L^{b-a} \sigma^{r-1}: K_{d 0}
$$

Equation (11) is plotted in Fig. 8. Since $\eta$ approaches 1 , the growth process is controlled by surface 


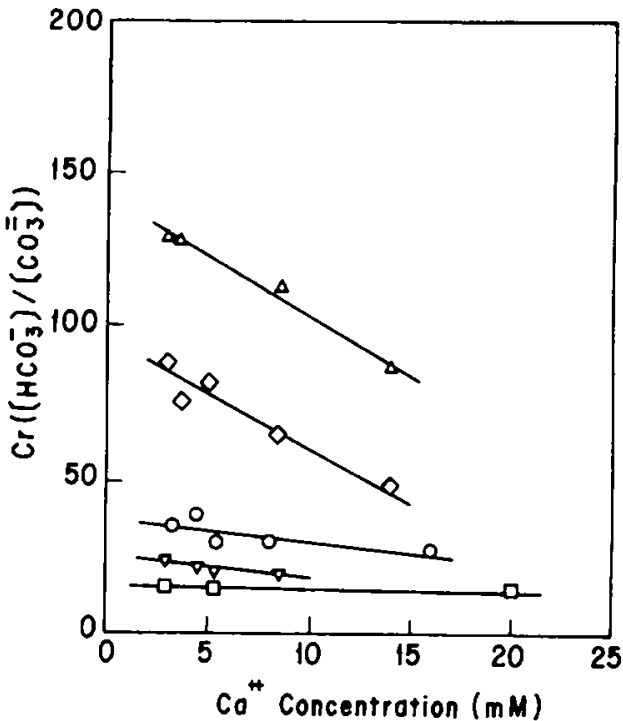

Fig. 5. Effect of calcium ion concentration on $\mathrm{Cr}$. ( $\triangle)$ $\mathrm{pH}=8.0,(\diamond) \mathrm{pH}=8.2,(\bigcirc) \mathrm{pH}=8.6,(\nabla) \mathrm{pH}=8.8$, (口) $\mathrm{pH}=9.0$.

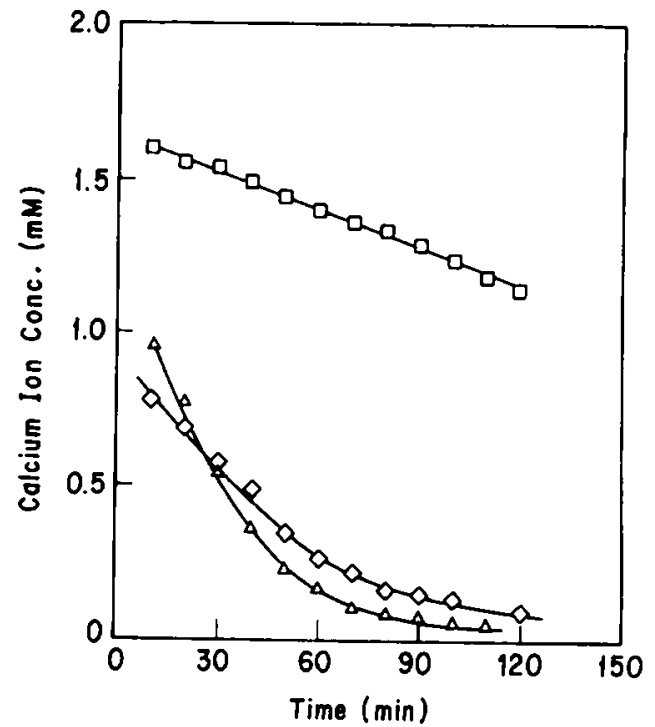

Fig. 6. $\mathrm{Ca}^{++}$concentration profiles. ( $\square$ ) Run no. 27, $(\triangle)$ Run no. 2, $(\diamond)$ Run no. 4.

integration. The result is consistent with many reports (Nancollas and Reddy, 1971; Kazmlerczak et al., 1982; Christoffersen and Christoffersen, 1990) for the growth of calcite.

\section{CONCLLSIONS}

A gas-liquid-solid reactive crystallizer was successfully operated under the condition of constant $\mathrm{pH}$ to study the formation of polymorphs of calcium carbonate and crystal growth of calcite. In the polymorph study the $\mathrm{CO}_{2}$ was introduced into the crystallizer by a gas sparger or a double-tube injection

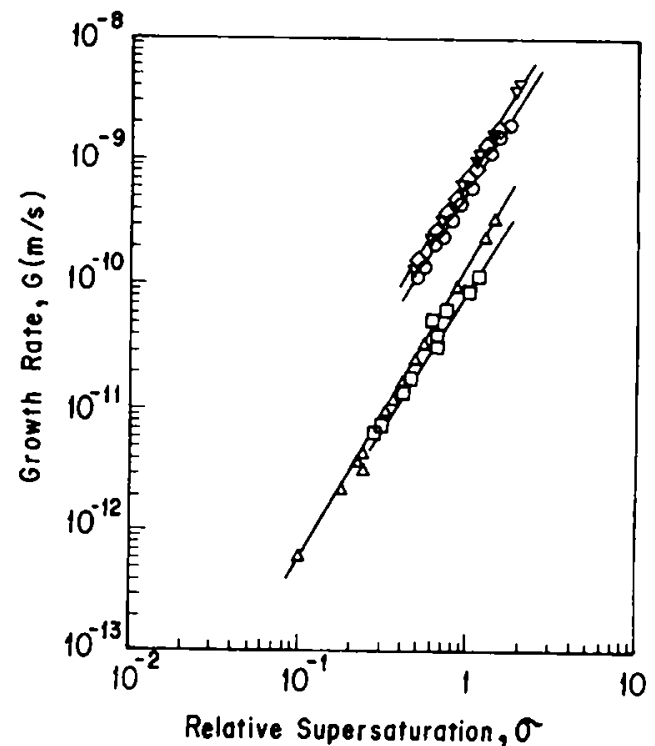

Fig. 7. Calcite crystal-growth rates. ([) $L=20 \mu \mathrm{m}$,

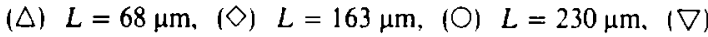
$L=328 \mu \mathrm{m}$.

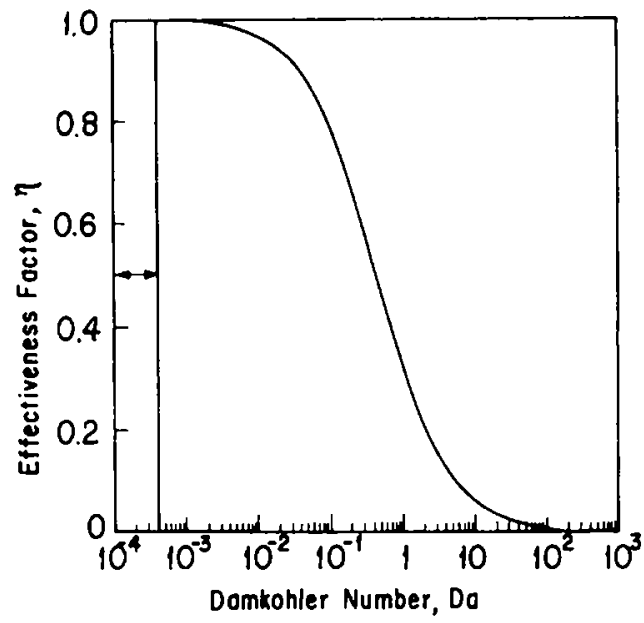

Fig. 8. Effectiveness factors of calcite growth.

nozzle; however, the gas sparger cannot be used in the crystal growth study. Among the operating variables investigated in this study, the $\mathrm{pH}$ of solution and calcium ion concentration are the important factors that determine the polymorphs of calcium carbonate. When operated at $30^{\circ} \mathrm{C}$, nearly pure products of vaterite are produced at $\mathrm{pH}$ below 8.0 in spite of the gas-dispersion method. The maximum yield of calcite occurs somewhere around the $\mathrm{pH}$ of 8.6. The yield of calcite is also influenced by the calcium ion concentration and gas-dispersion method. High concentration of calcium ion favors the formation of calcite. The aragonite is a minor product at $30^{\circ} \mathrm{C}$. The crystal growth rate of calcite seeds increases with increasing supersaturation and crystal size, and the crystal growth process is controlled by surface integration. 


\section{Acknowledgment}

This work was financially supported by the National Science Council of Republic China.

\section{YOTATION}

a exponent of crystal size in eq. (6)

$A \quad$ specific surface area, $\mathrm{m}^{2}$

$b \quad$ exponent of crystal size in eq. (7)

$\mathrm{Cr} \quad$ ratio of $\left[\mathrm{HCO}_{3}^{-}\right]$to $\left[\mathrm{CO}_{3}^{2-}\right]$

Da Damkohler number

is surface shape factor

fr. volume shape factor

$G$ linear growth rate, $\mathrm{m} / \mathrm{s}$

$K_{d} \quad$ mass-transfer coefficient, $m / s$

$K_{r} \quad$ surface-integration coefficient, $m$ :s

$K_{s p} \quad$ solubility product

$L \quad$ crystal sizc, $\mathrm{m}$

iM molecular weight, $\mathrm{kg} / \mathrm{kg}$ mole

m crystal mass, $\mathrm{kg}$

$R_{q} \quad$ mass growth rate. $\mathrm{kg} / \mathrm{m}^{2} \mathrm{~s}$

$r$ surface-reaction order

l time. min

$V \quad$ volume of solution. $\mathrm{m}^{3}$

$V$ v volume of crystal. $\mathrm{m}^{3}$

\section{Greek letters}

$\sigma \quad$ relative supersaturation

$\sigma_{i} \quad$ interfacial relative supersaturation

$\rho_{\mathrm{s}} \quad$ density, $\mathrm{kg} / \mathrm{m}^{3}$

$\eta \quad$ surface-integration effectiveness factor

$\Pi \quad$ ionic product

\section{REFEREYCES}

Butler, J. M. (1982) Carbon Dioxide Equilibria and Their Application, pp. 75-78. Addision-Wesley. London.

Chen, C.-Y. (1995) Crystal growth kinetics of calcium carbonate in a fluidized bed. Master thesis, National Taiwan University.

Christoffersen, J. and Christoffersen, M. R. (1990) Kinetics of spiral growth of calcite crystals and determination of the absolute rate constant. J. Crystal Growth 100, 203-211.

Garside, J. (1971) The concept of effectiveness factors in crystal growth, Chem. Engng Sci. 26, 1425-1430.

Hostomsky. J. and Jones, A. G. (1991) Calcium carbonate crystallization. agglomeration and form during continuous precipitation from solution. $J$ Phys. D 24, 165170.

Isopescu. R.. Mocioi, M., Zahanagiu. F. and Filipescu, L. (1996) Growth rate models and kinetics estimation for $\mathrm{CaCO}_{3}$ precipitated in continuous crystallizers. J. Cristal Growth 167, 260264.
Jones, A. G., Hostomsky, J. and Li, Z. (1992) On the effect of liquid mixing rate on primary crystal size during the Gas-Liquid precipitation of calcium carbonate. Chem. Engng Sci. 47. 3817-3824.

Kazmlerczak, T. F.. Tomson, M. B., and Nancollas. G. H. (1982) Crystal growth of calcium carbonate. A controlled composition kinetic study. J. Phys. Chem. 86, 103107.

Kojima, Y.. Sadotomo A.. Yasue, T. and Arai. Y. (1992) Control of crystal shape and modification of calcium carbonate prepared by precipitation from Calcium Hydrogencarbonate solution. I. Cercamic Soc. Japan Int. Ed. 100, 1128-1135.

Koutsoukos. P. G. (1993) Polymorphism in the calcium carbonate system. 12th Industrial Cristallization, 2-115-2-121. Warsaw, Poland.

Kubota, N. Sekimoto, T. and Shimizu. K. (1990) Precipitation of $\mathrm{BaCO}_{3}$ in a semibatch reactor with double-tube gas injection nozzle. J. Cristal Growth 102. 434-440.

Nancollas. G. B. (1966) Interaction in Electrolyte Solution. pp. 36 43. Elsevier. Amsterdam.

Nancollas, (j. H. and Reddy, M. M. (1971) The crystallization of calcium carbonate. II. Calcite growth mechanism. J. Colloid Interface Sci. 27. 824-832.

Nielsen, A. K. and Toft. J. M. (1984) Electrolyte crystal growth kinetics. J. Crystal Growth 67. 278-288.

Qui, Y. and Rasmuson, C. (1990) Growth and dissolution of succinic acid crystal in a bath stirred crystallizer, A.I.Ch.E. J. 36. 665-676.

Sherwood, T. K.. Piglord. R. J. and Wilke. C. R. (1975) Mass Transfer. pp. 336 343. McGrow-Hill. New York.

Sohnel, O. and Mullin. J. W. (1982) Precipitation of calcium carbonate. J. Cristal Growth 60. 239250

Tai, C. Y. and Chen. P. C. (1995) Nucleation, agglomcration and crystal morphology of calcium carbonate. A.I.Ch.E. J. 41, 68.77.

Tai, C. Y.. Chen. P. C. and Shih, S. M. (1993) Sizedependent growth and contact nucleation of calcite crystals. A.I.Ch.E. J. 39, 1472-1482.

Wachi, S. and Jones. A. G. (1991) Effect of gas-liquid mass transfer on crystal size distribution during the batch precipitation of calcium carbonatc. Che'm. Engng Sci. 46, 3289-3293.

Wojcik. J. A. and Jones, A. G. (1997) Experimental investigation into dynamics and stability of continuous MSMPR agglomerative precipitation of $\mathrm{CaCO}_{3}$ crystals. Trans. Instr. Chem. Engng 75. Part A, 113118 .

Wray, J. L. and Danicls. F. (1957) Precipitation of calcitc and aragonite. J. Am. Chem. Soc. 79. 2031-2034

Yagi. H.. Iwazawa, A., Sonobe, R., Matsubara, T. and Hikita. H. (1984) Crystallization of calcium carbonate accompanying chemical absorption. Ind. Engng Chem. Fundam. 23, 153158 